Original article

\title{
Cardiohemodynamics and gas analysis rearrangements in response to re-breathing in young males of Russia's Fareast
}

\author{
Inessa V. Averyanova \\ Scientific Research Center "Arktika", Fareastern Branch of the Russian Academy of Sciences, Magadan, Russia
}

Received 25 December 2019, Revised 8 May 2020, Accepted 28 May 2020

(C) 2019, Averyanova I.V.

(C) 2019, Russian Open Medical Journal

\begin{abstract}
The objective of this study was to examine the changes occurred in the heart rate variability, cardiovascular system and gas analysis in response to the test with return breathing in young Caucasian and Native men residing in Magadan region and Chukotka Autonomous District.

Methods - Total 345 young men were examined; of them 65 were Native people from Chukotka Autonomous District (ChAD) and 35 Natives from Magadan Region (MR) as well as Caucasians (48 from ChAD and 197 from MR, respectively).

Results - Studies have shown that in response to the hypoxic-hypercapnic effect, there were changes in the cardiovascular system, heart rate and gas analysis, with a number of differences depending on ethnicity and the region of residence. Region-related features of cardiohemodynamics were manifested by a more pronounced increase in the systolic blood pressure and heart rate in response to the rebreathing test in the two ethnic groups living in ChAD, which was observed against the background of higher values of the difference "baseline-test" in carbon dioxide levels in the exhaled air. Ethnic differences in our studies were seen due to the pronounced increase in response to the test for the activity of the parasympathetic link of the autonomic nervous system (increased TP and HF), at the background of a decrease in VLF observed only among Caucasians, which was associated with the lowest oxygen concentration in the exhaled air at the peak of the test. It was found that the significant differences in gas analysis identified at rest and at the peak of the test as well as rearrangements of the heart rate and cardiovascular system characteristics in response to the re-breathing in the young subjects residing in different regions of northeast Russia and belonging to different ethnic groups can serve as informative criteria reflecting the region caused ethnic characteristics of the organism.

Conclusion - It was found, the most visible and informative parameters for the differences in dynamics of the studied systems demonstrated by the subjects of the two ethnic groups in the two observed regions of the Far East in response to a hypoxic-hypercapnic test with return breathing have been the spectral characteristics of the heart rate (TP, HF, VLF) and gas analysis with the calculation of the difference between the baseline and the peak values (difference in the $\mathrm{CO}_{2}$ and $\mathrm{O}_{2}$ concentration of the test-baseline).
\end{abstract}

Keywords: young men, heart rate variability, cardiovascular system, gas analysis, re-breathing test.

Cite as Averyanova IV. Cardiohemodynamics and gas analysis rearrangements in response to re-breathing in young males of Russia's Fareast. Russian Open Medical Journal 2020; 9: e0203.

Correspondence to Inessa V. Averyanova. Address: Scientific Research Center "Arktika", Fareastern Branch of the Russian Academy of Sciences, 24 Karl Marx St. Magadan, 685000, Russia. Phone: +79246911146. E-mail: Inessa1382@mail.ru.

\section{Introduction}

Changes in the cardiac rhythm consider a universal and operative response of the whole organism to the influence of environmental factors and reflect the balance between the tone of the parasympathetic and sympathetic parts of the Autonomic Nervous System (ANS) [1].

It is well known that Heart Rate Variability is closely related to respiration [2]. The main reasons for that are due to the fact that breathing and heart rate, as well as blood pressure are parts of the cardiorespiratory system which is also regulated by the ANS in the form of a connected system with feedback control [3]. For example, Heart Rate tends to increase in response to hypoxia or hypercapnia in healthy subjects [4]. This interaction is manifested by activation of baroreceptors when the change in Blood Pressure affects the Heart Rate based on negative feedback [5]. Besides, this interaction is reflected in respiratory sinus arrhythmia which is associated with a high frequency (HF component) in the range of cardiac rhythm. Sinus arrhythmia is aimed at comparing perfusion with the Heart Rhythm and regulating the gas exchange rate in the alveoli [6], and can be interpreted as the effect of respiration on the sinus node of the heart [7].

The aim of the research is to study the restructuring of cardiac rhythm, gas analysis, and the cardiovascular system in young male vago- normotonia subjects residing in Magadan Region (MO) and 
Chukotka Autonomous District (ChAD) while performing a rebreathing test.

\section{Material and Methods}

\section{Subjects}

The study involved 345 young men; of them 65 were natives from Chukotka Autonomous District and 35 native people living in Magadan Region as well as Caucasians (48 from the ChAD and 197 from the MO). Only young male vago- normotonia subjects participated in the study. Such selection was mainly caused by the necessity to form a homogeneous group in which, in response to the functional test as a disturbing factor, similar reactions of rearrangements of the parasympathetic and sympathetic links would be expected to happen, and differences would be determined by stratification factors such as ethnicity and region of residence. At the same time, it should be noted the predominance of young male vago- normotonia subjects in the studied samples. All subjects were students of higher and secondary institutions and had a comparable lifestyle.

\section{Study of gas exchange indicators}

As a functional test, a test with return breath (re-breathing) without $\mathrm{CO}_{2}$ absorption was used. Immediately prior to the test, we used a portable gas analyzer manufactured by "Karbonik" to determine the content of $\mathrm{CO}_{2}(\%)$ and $\mathrm{O}_{2}(\%)$ in the subjects' exhaled air. To carry out the test, the subject, with the nose closed with a clip, had to make three deep exhalations in a plastic sealed bag (such as Douglas) from where the process of inhalation and exhalation was further performed with a total duration of three minutes [8]. After completion of the test with return breathing, the gas mixture remained in the sealed bag was analyzed on the percentage level of $\mathrm{CO}_{2}$ and $\mathrm{O}_{2}$ using the same instrument.

\section{Study of heart rate variability indicators}

At rest, before performing the breathing test and during its three minute run using a Varikard instrument and VARICARDKARDi software, a cardiac rhythmogram was recorded based on the methodological recommendations $[9,10]$. The following Heart Rate Variability (HRV) parameters were analyzed: mode (Mo, ms) as the most common value of the R-R interval; the difference between the maximum and minimum values of cardiointervals (MxDMn, ms); the number of pairs of cardiointervals with a difference of more than $50 \mathrm{~ms}$ in \% of the total number of cardiointervals (pNN50, ms); the square root of the sum of the differences in the series of cardiointervals (RMSSD, ms), standard deviation of the complete range of cardiointervals (SDNN, ms); mode amplitude with a class width of $50 \mathrm{~ms}$ (AMo 50\%, ms); Stress Index of regulatory systems (SI, standard units); Total Power of heart rate spectrum (TP, $\mathrm{ms}^{2}$ ), spectrum power of the highfrequency component of Heart Rate Variability in the range of 0.4$0.15 \mathrm{~Hz}$ (respiratory waves) ( $\left.\mathrm{HF}, \mathrm{ms}^{2}, \%\right)$; spectrum power of the low-frequency component of Heart Rate Variability in the range of $0.15-04 \mathrm{~Hz}\left(\mathrm{LF}, \mathrm{ms}^{2}, \%\right)$; the power of the spectrum of the Very Low-Frequency component of heart rate variability in the range of 0.04-0.015 Hz (VLF, $\left.\mathrm{ms}^{2}, \%\right)$.

\section{Study of indicators of the cardiovascular system}

Using a Nessei DS-1862 Automatic Blood Pressure Monitor (Japan), we analyzed the Systolic and Diastolic Blood Pressure indicators at rest before the test and at the peak of the test (the end of the 3rd minute), with simultaneous recording the level of oxyhemoglobin $\left(\mathrm{HbO}_{2}, \%\right)$ using the "NPB-40" Pulse Oximeter (USA). All studies were conducted in mornings, in a room with a comfortable temperature of $19-21^{\circ} \mathrm{C}$.

\section{Statistical analysis}

The results were statistically processed using the Statistica 7.0 application software package. The distribution of the measured variables was checked for normality based on the Shapiro-Wilk test. The results of nonparametric processing methods are presented in the form of the median with lower and upper quartiles - Me (LQ, UQ), and parametric as the average value and its error $-M \pm m$. The statistical significance of the differences was determined using the $t$ criterion, that is the Student criterion for dependent samples with a normal distribution and the nonparametric Wilconson criterion for samples with a distribution other than normal. To determine the differences between independent samples in the case of a normal distribution, the $t$ Student test for independent samples was used; for a distribution that differs from the normal, the Mann-Whitney criterion was used. The critical significance level $(p)$ in the work was taken to be equal to or less than 0.05 [11].

\section{Results}

Table 1 presents the main indicators of gas analysis and the cardiovascular system at rest before re-breathing and at the peak of the test in young male Natives and Caucasians living in Magadan Region and Chukotka Autonomous District. The results indicate that, at rest young male subjects of the two ethnic groups from the both cities of Magadan and Anadyr demonstrated no statistically significant differences in all the studied characteristics. At the same time, intergroup region-related differences were recorded only with respect to gas analysis indices: the Anadyr subjects were lower in the exhaled air Carbon Dioxide and higher in Oxygen concentration. The Caucasian subjects from the two territories, at the peak of re-breathing showed statistically lower indicators of Oxygen concentration in the exhaled air as compared to those of the Natives. An analysis of intergroup differences revealed higher $\mathrm{BP}_{\mathrm{S}}$ and $\mathrm{HR}$, against the background of significantly lower $B P_{D}$ values in the group of young men of the two ethnic groups inhabiting the territory of the ChAD. It should be noted the lowest concentration of $\mathrm{O}_{2}$ in the exhaled air of the Caucasian subjects of the city of Magadan.

Table 2 presents the indicators of cardiac rhythm in young men of the two ethnic groups and two regions of residence at rest and at the peak of the hypoxic-hypercapnic test. From the results of the study, the lowest baseline indices of the LF power of the HRV spectrum were noted in the group of Chukotka Natives. At the peak of re-breathing, statistically and significantly lower Mo indices were recorded in the group of ChAD Caucasians. At the same time, higher rates of TP, HF, and LF at the peak of the test were observed in Caucasians of the two areas. Intergroup ethnic differences at the peak of respiration could only be seen in the values of AMo and SI which were found to be lower in the group of Magadan region Caucasians. 
Table 1. Indicators of gas analysis, cardiovascular system and arterial blood oxygenation at rest and at the peak of the test with re-breathing in young male vago- normotonia subjects, Europeans and Aborigines, residing in Magadan Region and Chukotka Autonomous District

\begin{tabular}{|c|c|c|c|c|c|c|c|c|}
\hline \multirow[t]{2}{*}{ Studied indicators } & \multicolumn{4}{|c|}{ Experiment stage } & \multicolumn{4}{|c|}{ Difference Significance Rate } \\
\hline & \multicolumn{2}{|c|}{ Indicators at rest } & \multicolumn{2}{|c|}{ Re-breathing } & 1 vs 2 & 3 vs 4 & 1 vs 3 & 2 vs 4 \\
\hline & \multicolumn{4}{|c|}{ Chukotka Autonomous District } & & & & \\
\hline & Aboriginals (1) & Caucasians (2) & Aboriginals (3) & Caucasians (4) & & & & \\
\hline $\mathrm{BP}_{\mathrm{s}}, \mathrm{mm} \mathrm{Hg}$ & $128.5 \pm 1.4$ & $127.1 \pm 1.3$ & $141.4 \pm 2.4^{*}$ & $138.2 \pm 2.2^{*}$ & $p=0.512$ & $\mathrm{p}=0.285$ & $\mathrm{p}<0.001$ & $\mathrm{p}<0.001$ \\
\hline $\mathrm{BP}_{\mathrm{D}}, \mathrm{mm} \mathrm{Hg}$ & $73.8 \pm 1.1$ & $73.2 \pm 1.2$ & $78.8 \pm 1.1^{*}$ & $77.5 \pm 1.7^{*}$ & $p=0.744$ & $p=0.612$ & $\mathrm{p}<0.011$ & $p<0.025$ \\
\hline $\mathrm{HR}$, beats per min & $70.7 \pm 1.0$ & $71.3 \pm 1.6$ & $77.5 \pm 1.4^{*}$ & $81.3 \pm 1.8^{*}$ & $p=0.762$ & $p=0.091$ & $p<0.001$ & $p<0.001$ \\
\hline $\mathrm{CO}_{2}$ concentration, $\%$ & $3.2 \pm 0.1^{*}$ & $3.1 \pm 0.1^{*}$ & $7.3 \pm 0.7$ & $6.8 \pm 0.2$ & $p=0.445$ & $p=0.356$ & $p<0.001$ & $p<0.001$ \\
\hline $\mathrm{O}_{2}$ concentration, $\%$ & $17.0 \pm 0.1^{*}$ & $17.1 \pm 0.1^{*}$ & $13.4 \pm 0.2$ & $13.1 \pm 0.2^{*}$ & $p=0.362$ & $p<0.052$ & $p<0.001$ & $p<0.001$ \\
\hline \multirow[t]{2}{*}{$\mathrm{HbO}_{2}, \%$} & $98.5 \pm 0.1$ & $98.5 \pm 0.1$ & $95.6 \pm 0.3$ & $95.7 \pm 0.4$ & $p=0.901$ & $p=0.861$ & $p<0.001$ & $p<0.001$ \\
\hline & & & Magadan region & & & & & \\
\hline $\mathrm{BP}_{\mathrm{s}}, \mathrm{mm} \mathrm{Hg}$ & $127.3 \pm 2.3$ & $125.5 \pm 0.9$ & $129.8 \pm 2.9$ & $127.7 \pm 1.1$ & $p=0.494$ & $p=0.515$ & $p=0.260$ & $p=0.061$ \\
\hline $\mathrm{BP}_{\mathrm{D}}, \mathrm{mm} \mathrm{Hg}$ & $75.6 \pm 1.8$ & $73.7 \pm 0.8$ & $89.0 \pm 3.0$ & $84.1 \pm 1.4$ & $p=0.325$ & $p=0.172$ & $p<0.001$ & $p<0.001$ \\
\hline $\mathrm{HR}$, beats per min & $68.8 \pm 2.3$ & $69.8 \pm 0.8$ & $73.5 \pm 2.5$ & $74.2 \pm 0.9$ & $p=0.687$ & $p=0.631$ & $p<0.033$ & $p<0.045$ \\
\hline $\mathrm{CO}_{2}$ concentration, $\%$ & $3.8 \pm 0.2$ & $3.7 \pm 0.1$ & $6.6 \pm 0.2$ & $6.9 \pm 0.1$ & $p=0.431$ & $p=0.112$ & $p<0.001$ & $p<0.001$ \\
\hline $\mathrm{O}_{2}$ concentration, $\%$ & $16.3 \pm 0.2$ & $16.4 \pm 0.1$ & $13.1 \pm 0.3$ & $12.5 \pm 0.1$ & $p=0.582$ & $p<0.049$ & $p<0.001$ & $p<0.001$ \\
\hline $\mathrm{HbO}_{2}, \%$ & $98.6 \pm 0.1$ & $98.5 \pm 0.1$ & $95.6 \pm 0.4$ & $96.2 \pm 0.2$ & $p=0.525$ & $p=0.191$ & $p<0.001$ & $p<0.001$ \\
\hline
\end{tabular}

* - statistically significant differences between the subjects from Magadan Region and the ChAD.

Table 2. Indicators of Heart Rate Variability at rest and at the peak of the test with return breathing in young male Aboriginals and Caucasians (vagonormotonia subjects) residing in Magadan Region and Chukotka Autonomous District

\begin{tabular}{|c|c|c|c|c|c|c|c|c|}
\hline \multirow{3}{*}{$\begin{array}{l}\text { Studied } \\
\text { indicators }\end{array}$} & \multicolumn{4}{|c|}{$C h A D$} & \multicolumn{4}{|c|}{ Difference Significance Rate } \\
\hline & \multicolumn{2}{|c|}{ Indicators at rest } & \multicolumn{2}{|c|}{ Re-breathing } & 1 vs 2 & 3 vs 4 & 1 vs 3 & 2 vs 4 \\
\hline & Aboriginals (1) & Caucasians (2) & Aboriginals (3) & Caucasians (4) & & & & \\
\hline MxDMn, ms & $306.7(261.3,397.5)$ & $376.1(284.1,417.2)$ & $341.1(265.0,432.0)$ & $362.0(293.3,442.3)$ & $p=0.162$ & $p=0.272$ & $p<0.049$ & $p=0.422$ \\
\hline RMSSD, ms & $47.2(35.1,58.6)$ & $48.1(32.0,65.2)$ & $55.6(43.1,77.1)$ & $57.7(42.1,86.6)$ & $p=0.572$ & $p=0.761$ & $p<0.001$ & $p<0.001$ \\
\hline pNN50, \% & $26.6(14.6,37.1)$ & $23.8(12.1,47.4)$ & $34.8(24.1,52.6)$ & $36.5(21.2,47.2)$ & $p=0.921$ & $p=0.512$ & $p<0.001$ & $p<0.001$ \\
\hline SDNN, ms & $58.6(46.4,72.7)$ & $66.2(48.4,85.1)$ & $69.5(49.7,87.2)$ & $76.2(58.6,87.5)$ & $p=0.111$ & $p=0.443$ & $p<0.001$ & $p<0.052$ \\
\hline Mo, ms & $869.1(773.2,884.6)$ & $823.5(727.1,878.2)$ & $775.9(683.1,875.6)$ & $724.2(675.5,776.3)$ & $p=0.313$ & $p<0.052$ & $p<0.001$ & $p<0.001$ \\
\hline AMo, ms & $33.5(28.8,41.5)$ & $31.8(24.2,38.8)$ & $29.8(24.2,36.7)$ & $27.5(23.8,36.7)^{*}$ & $p=0.081$ & $p=0.871$ & $p<0.001$ & $p=0.353$ \\
\hline SI, c. u. & $62.3(43.6,102.2)$ & $49.1(37.5,93.2)$ & $58.3(33.1,101.7)$ & $52.3(39.6,79.8)^{*}$ & $p=0.223$ & $p=0.673$ & $p=0.242$ & $p=0.584$ \\
\hline $\mathrm{TP}, \mathrm{ms}^{2}$ & $3020.7(1780.3,4090.2)$ & $3840.8(1906.5,4940.2)$ & $3265.6(1537.8,5121.2)$ & $4557.8(2125.2,7307.2)$ & $p=0.134$ & $p<0.054$ & $p=0.144$ & $p<0.054$ \\
\hline $\mathrm{HF}, \mathrm{ms}^{2}$ & $957.6(475.4,1327.3)$ & $1081.2(375.7,1937.8)$ & $1442.8(642.7,2463.7)$ & $1917.5(738.7,4172.5)$ & $p=0.464$ & $p<0.050$ & $p<0.001$ & $p<0.001$ \\
\hline $\mathrm{LF}, \mathrm{ms}^{2}$ & $864.2(627.3,1202.2)^{*}$ & $1333.8(837.3,1578.5)$ & $716.6(452.3,1195.6)$ & $1187.2(604.2,2167.6)$ & $p<0.049$ & $p<0.050$ & $p=0.232$ & $p=0.942$ \\
\hline VLF, $\mathrm{ms}^{2}$ & $503.7(273.6,732.6)$ & $628.2(374.8,1002.2)$ & $438.4(202.5,654.7)$ & $504.6(241.2,996.8)$ & $p=0.070$ & $p=0.271$ & $p=0.381$ & $p<0.048$ \\
\hline LF/HF, c. u. & . . . . . . . & _ . . . . . $1.2(0.7,2.4)$ & $\begin{array}{c}0.5(0.4,0.7) \\
\text { Magadan region }\end{array}$ & $0.8(0.5,1.2)$ & $p=0.821$ & $p=0.135$ & $p<0.001$ & $p<0.001$ \\
\hline MxDMn, ms & $357.2(281.8,508.2)$ & $367.3(291.2,458.7)$ & $367.2(308.6,513.7)$ & $397.6(318.2,501.4)$ & $p=0.623$ & $p=0.323$ & $p=0.334$ & $p<0.001$ \\
\hline RMSSD, ms & $46.6(35.6,68.7)$ & $46.3(37.4,64.6)$ & $56.2(42.8,80.5)$ & $62.2(46.8,83.2)$ & $p=0.874$ & $p=0.282$ & $p<0.001$ & $p<0.001$ \\
\hline pNN50, \% & $26.5(12.7,44.5)$ & $21.3(12.7,34.2)$ & $39.2(22.1,51.5)$ & $37.8(25.2,52.8)$ & $p=0.364$ & $p=0.454$ & $p<0.001$ & $p<0.001$ \\
\hline SDNN, ms & $61.3(53.4,83.2)$ & $68.1(53.5,83.8)$ & $71.6(57.7,96.6)$ & $78.5(61.4,105.1)$ & $p=0.335$ & $p=0.288$ & $p<0.065$ & $p<0.001$ \\
\hline Mo, ms & $876.4(771.8,975.5)$ & $826.5(773.1,927.5)$ & $774.7(676.2,874.5)$ & $772.4(675.7,874.6)$ & $p=0.552$ & $p=0.624$ & $p<0.001$ & $p<0.001$ \\
\hline AMo, ms & $30.3(25.2,38.6)$ & $30.4(26.1,37.4)$ & $27.6(21.5,33.4)$ & $26.5(22.6,32.2)$ & $p=0.938$ & $p=0.412$ & $p<0.001$ & $p<0.001$ \\
\hline SI, c. u. & $53.8(28.3,98.2)$ & $48.5(32.4,78.6)$ & $58.5(25.2,75.3)$ & $40.7(28.4,63.5)$ & $p=0.777$ & $p=0.432$ & $p=0.222$ & $p<0.001$ \\
\hline $\mathrm{TP}, \mathrm{ms}^{2}$ & $3526.8(2355.3,5343.4)$ & $3752.8(2386.3,5872.5)$ & $3625.4(2492.8,8238.6)$ & $4967.4(3015.7,7424.4)$ & $p=0.671$ & $p<0.042$ & $p=0.133$ & $p<0.001$ \\
\hline $\mathrm{HF}, \mathrm{ms}^{2}$ & $1098.7(478.4,2021.7)$ & $872.4(500.5,1542.3)$ & $1685.4(1063.4,3333.8)$ & $2061.4(1138.2,3494.6)$ & $p=0.572$ & $p<0.049$ & $p<0.001$ & $p<0.001$ \\
\hline $\mathrm{LF}, \mathrm{ms}^{2}$ & $1451.3(828.1,2730.5)$ & $1352.5(927.4,2116.7)$ & $844.1(655.7,2024.5)$ & $1091.5(751.2,2392.8)$ & $p=0.742$ & $p<0.066$ & $p<0.031$ & $p<0.049$ \\
\hline VLF, $\mathrm{ms}^{2}$ & $511.4(254.7,1043.2)$ & $591.6(362.5,967.4)$ & $463.2(272.1,986.3)$ & $506.5(283.2,826.5)$ & $p=0.168$ & $p=0.982$ & $p=0.872$ & $p<0.001$ \\
\hline LF/HF, c. u. & $1.4(0.6,2.7)$ & $1.6(1.1,2.6)$ & $0.6(0.4,1.3)$ & $0.6(0.4,1.3)$ & $p=0.813$ & $p=0.834$ & $p<0.001$ & $p<0.001$ \\
\hline
\end{tabular}

* - statistically significant differences between groups from the examined territories of Fareast Region.

\section{Discussion}

The analysis of the changes in the cardiovascular system revealed a more pronounced response of its indicators to the hypoxic-hypercapnic test in the group of the subjects (Table 1) from ChAD, regardless of their ethnicity, which was manifested by a statistically significant increase in all the studied characteristics. In the group of Magadan young males, no significant dynamics of $\mathrm{BP}_{\mathrm{S}}$, as compared to the baseline, was found at the peak of the rebreathing test, while the $\mathrm{BP}_{\mathrm{D}}$ and $\mathrm{HR}$ values at the peak of the test were statistically higher than those at rest. The results of the study indicate that, the young men of the two ethnic groups of ChAD had lower baseline values of Carbon Dioxide in the exhaled air, and higher concentration of Oxygen in the exhaled air in comparison with the subjects of Magadan. At the peak of the test, the differences in $\mathrm{CO}_{2}$ were leveled, while both Magadan and Anadyr Caucasians demonstrated statistically and significantly lower, as compared to the Natives, values of $\mathrm{O}_{2}$ in the exhaled air. The significant differences in gas analysis indices, both at rest and the peak of the test, revealed in the subjects from different regions of the North-East of Russia belonging to different ethnic groups, can be characteristics that reflect the region-related and ethnic profiles of the body. 
The analysis of the baseline values of the statistical and the cardiac rhythm spectral characteristics (Table 2) discovered no fundamental region-related or ethnic differences, while statistically and significantly higher TP, HF, and LF indices were observed at the peak of the return breathing test in the Caucasians of the two regions, as compared to those of the Native subjects. These differences could be caused by a pronounced increase in the total and high-frequency components of the spectrum of the Heart Rhythm in response to re-breathing in the Caucasoid group, which is a reflection of parasympathetic activation. The higher values of the low-frequency component in the Caucasoid group are associated with statistically and significantly lower LF values at rest against the background of the absence of significant dynamics in response to the test in the Anadyr Natives, and also due to a decrease in the test in the Native subjects of Magadan, which distinguishes this group from the rest. The performed comparative analysis of the changes in characteristics of the heart rate variability (Table 2 ) in response to the re-breathing test testifies to various mechanisms for maintaining the basic characteristics of the cardiovascular system (Heart Rate, $\mathrm{BP}_{\mathrm{S}}$ and $\mathrm{BP}_{\mathrm{D}}$ ) and gas analysis, depending on ethnicity and the region of residence. Despite a similar pattern of cardiac rhythm rearrangements (an increase in RMSSD, pNN50, SDNN, HF and a decrease in Mo) reflecting the activation of the parasympathetic link in response to the respiration test, a number of fundamental differences were noted. From the above data it follows that, a more pronounced dynamics at the peak of the test of the high-frequency component of the spectrum was typical of Magadan Caucasians (more than $135 \%)$ and the Caucasians of ChAD (78\%). In the groups of Native people the increase in this component of the spectrum varied within $50-53 \%$. It is known that the high-frequency component of the HRV spectrum clearly coincides with the respiratory rate and is a reflection of respiratory sinus arrhythmia. The degree of its increase indicates the activity of parasympathetic effects on the sinus node [12]. Such a marked increase in the respiratory waves of HRV in Caucasians, apparently, is aimed at increasing the rate of gas exchange in the alveoli [6]. After R. Perini et al. (1990) [13], the high-frequency component of the cardiac rhythm is associated with the level of Oxygen consumption. Having analyzed the difference in the baseline-test of Oxygen concentration in the exhaled air, we found that to be ethnically conditioned, which was manifested by higher values of this indicator in the Caucasoid group (3.9\% in Magadan Caucasians and $4.0 \%$ in the inhabitants of ChAD), while for the Native group, this difference was $3.6 \%$ among representatives of the ChAD and 3.2\% among those of Magadan. Such profiles of the dynamics of gas analysis indicators against the background of low values of $\mathrm{O}_{2}$ concentration in the exhaled air at the peak of re-breathing, only observed in the group of Caucasians, reflecting its active consumption under hypoxichypercapnic effects on the body, can cause such a pronounced increase in the HF component of cardiac rhythm. It should be noted that the adjustments of HRV indices in the group of Caucasians of the two regions have proved to occur against the background of a significant reduction in the VLF component of the spectrum, which decrease, according to the authors [14], reflects deficient manifestations of the energy-metabolic status of the body.

In the group of Magadan Natives, the return breathing caused a decrease in the low-frequency component of the heart rhythm, which distinguishes the examined sample from the other groups of the subjects. The LF frequencies of the Cardiac Rhythm spectrum are currently considered to be an activator of fluctuations in the rhythm of Blood Pressure realized through baroreflex mechanisms $[15,16]$. With increasing Blood Pressure, afferent impulses from the baroreceptors enter the cardioinhibitory and vasomotor centers of the medulla oblongata and inhibit sympathetic modulation but activate parasympathetic modulation, which leads to a decrease in the tone of sympathetic vasoconstrictor fibers and, in turn, causes a decrease in Heart Rate [5]. Lowered impulses from baroreceptors indirectly judged by the reduced LF [17] at the peak of re-breathing in the group of Native people of MR, may indicate a baroreflex dysregulation, which leads to activation of vasomotor tone. This is generally consistent with the most pronounced increase in Diastolic Blood Pressure at the peak of the test and distinguishes this sample from the rest. Moreover, in this group, no significant dynamics of TP and MxDMn were revealed and the lowest activity of the HF component of the rhythm in response to the test was noted, which reflects the less pronounced inhibitory effect of the parasympathetic part of the Autonomic Nervous System on the Heart Rhythm. It should be noted that in the rest examined groups there was no decrease in the LF component of the spectrum in response to re-breathing, which, based on the physiological interpretation of this indicator, may reflect a lack of activation of the baroreflex regulation of hemodynamic parameters against the background of an increase in Blood Pressure (in the two groups of Anadyr subjects there was an increase in both $\mathrm{BP}_{S}$ and $\mathrm{BP}_{\mathrm{D}}$, and among Magadan subjects of the two ethnic groups only an increase in $\mathrm{BP}_{\mathrm{D}}$ was observed). At the same time, in the group of Magadan Natives, low-frequency component of the spectrum can suggest the dysfunction of the baroreflex control of hemodynamic parameters, which leads to the activation of vasomotor tone and can be seen against the background of the least parasympathetic activity, and therefore leads to the pronounced increase in $\mathrm{BP}_{\mathrm{D}}$. It can be assumed that the inhibition of the baroreflex regulation of the cardiovascular system is the result of chemoreflex activation in response to hypoxic-hypercapnic effects, which increases the tone of the sympathetic nervous system and, in turn, leads to an increase in Blood Pressure, as well as Heart Rate. This mostly happens due to the fact that chemoreflexes play a dominant role in the regulation of ventilation and cardiovascular autonomic reactions $[18,19,20]$. The result of chemoreflex activation is an increase in the tone of the Sympathetic Nervous System (which makes Blood Pressure higher) and inhibition of the baroreflex regulation of the cardiovascular system, which is the result of complex mechanisms of interaction between baro- and chemoreflexes since the sensitivity of the arterial baroreflex is inversely proportional to the sensitivity of peripheral chemoreflex [5]. In addition, hypercapnia is the main factor affecting sympathetic modulation [21]. Accounting for the fact that it is the $\mathrm{CO}_{2}$ level that supports the important role of central chemoreflex, it can be assumed that the more pronounced activation of chemoreflex regulation, demonstrated by the young men of both Native and Caucasoid people living in the territory of the ChAD, is apparently associated with an initially increased sensitivity to excess $\mathrm{CO}_{2}$ and lack of $\mathrm{O}_{2}$ and manifests itself in a statistically and significantly lower values of these indicators at rest. In confirmation of this, higher values of the difference in the $\mathrm{CO}_{2}$ concentration of the test-baseline were noted precisely in the group of young men of the ChAD and amounted to $4.1 \%$ in the group of Native people and $3.7 \%$ in the group of Caucasians. In the subjects of Magadan this difference was $2.8 \%$ and $3.2 \%$, respectively. Despite the fact that the young 
men of the four groups, in response to re-breathing, showed the activation of the parasympathetic department of the Autonomic Nervous System which is aimed at inhibitory autonomic effects on the stabilization of Heart Rate, that is not confirmed in our studies and is reflected in an increase in Heart Rate in response to the return breathing in all the examinees.

Thus, it can be assumed that an increase in the concentration of $\mathrm{CO}_{2}$ in the inhaled air at the peak of the hypoxic-hypercapnic effect on the body is comparable to an increase in Blood Pressure, which occurs against the background of activation of the Sympathetic Nervous System through central chemoreceptors, and an increase in Heart Rate is observed due to the limited possibility of baroreceptor regulation to activate the necessary level of parasympathetic activity for providing inhibitory autonomic effects on Heart Rate stabilization.

The arterial blood saturation index in our study is an uninformative marker for determining changes in functional indicators in response to a test with return breathing.

Thus, the studies showed that in response to the hypoxichypercapnic test with return breathing, there are a number of differences in the restructuring of the indicators of the cardiovascular system, gas analysis and Heart Rate Variability depending on the region of residence and ethnicity. Ethnic differences showed pronounced TP and HF increase in response to the test against the background of VLF decrease which could be observed in young Caucasian men only. The Caucasian subjects of the two studied regions demonstrated the lowest oxygen concentration at the peak of the test which apparently led to a pronounced extension of the respiratory waves (HF component of the spectrum), aimed at improving the perfusion in the lungs, and as a result, oxygen debt manifested itself in a decrease in VLF of HRV waves. Based on this, the high values of the HF component of the Heart Rhythm at the peak of respiration may reflect an increased level of oxygen consumption (as evidenced by the difference between the background and peak values of oxygen concentration in exhaled air), and the resulting deficiency in the energy-metabolic status was manifested by negative dynamics of the VLF component of the spectrum. These features in the restructuring of the pattern of cardiac rhythm characteristics may be criteria reflecting the physiological distinctive features of ethnicity. Moreover, in the Natives of MR, a decrease in the lowfrequency component of the HRV spectrum may reflect inhibition of baroreflex regulation, which was not observed in other examined groups. Regional features of the restructuring of the indicators of cardiohemodynamics were manifested by a more pronounced increase in Systolic Blood Pressure and Heart Rate in young men of the two ethnic groups inhabiting ChAD, which was found against the background of higher values of the difference in the baseline test in the level of Carbon Dioxide in the exhaled air.

\section{Conclusion}

From the above it should be noted that the significant differences in gas analysis indices seen at rest and at the peak of the test $\left(\mathrm{CO}_{2}\right.$ concentration of the test-baseline) as well as rearrangements of the cardiac rhythm (TP, HF, VLF), and cardiovascular system (HR) in response to the return breathing in young men living in different regions of Northeast Russia and belonging to different ethnic groups, can serve informative criteria that reflect the regional and ethnic characteristics of the body.

\section{Ethical approval}

The study was carried out in accordance with the principles of the Helsinki Declaration. The study protocol was approved by the Ethics Committee of Biomedical Research at the Northeast Scientific Center of the Far Eastern Branch of the Russian Academy of Sciences (No. 004/013 dated 12/10/2013). All investigations were performed with the written informed consent of volunteers and subject to biomedical ethic rules.

\section{Funding}

Budget financing of the "Arktika" Scientific Research Center, FEB RAS within the framework of the research theme entitled "Study of the physiological mechanisms of cross-adaptation (hypoxia, cold, hypercapnia) and their trace reactions in humans for the purpose of selecting and predicting their performance in extreme climatic and technogenic environmental conditions".

\section{Conflict of interest}

The authors declare no apparent or potential conflicts of interest related to the publication of this article.

\section{References}

1. Jose $A D$, Collison $D$. The normal range and determinants of the intrinsic heart rate in man. Cardiovasc Res 1970; 4(2): 160-167. https://doi.org/10.1093/cvr/4.2.160.

2. Bailon R, Laguna P, Mainardi L, Sornmo L. Analysis of heart rate variability using time-varying frequency bands based on respiratory frequency. Conf Proc IEEE Eng Med Biol Soc 2007; 2007: 6675-6678. https://doi.org/10.1109/iembs.2007.4353891.

3. Ursino M. Interaction between carotid baroregulation and the pulsating heart: a mathematical model. Am J Physiol 1998; 275(5): H1733-H1747. https://doi.org/10.1152/ajpheart.1998.275.5.h1733.

4. Kronenberg RS, Drage CW. Attenuation of the ventilatory and heart rate responses to hypoxia and hypercapnia with aging in normal men. $J$ Clin Invest 1973; 52(8): 1812-1819. https://doi.org/10.1172/jci107363.

5. Berne RM, Levy MN. Cardiovascular physiology, 7th ed. St. Louis: Mosby-Year Book: Inc., 1997: 324 p. https://openlibrary.org/books/OL990546M/Cardiovascular_physiology.

6. Yasuma F, Hayano J. Respiratory sinus arrhythmia: why does the heartbeat synchronize with respiratory rhythm? Chest 2004; 125(2): 683-690. https://doi.org/10.1378/chest.125.2.683.

7. Berntson GG, Bigger JT Jr, Eckberg DL, Grossman P, Kaufmann PG, Malik M, et al. Heart rate variability: origins, methods, and interpretive caveats. Psychophysiology 1997; 34(6): 623-648. https://doi.org/10.1111/i.1469-8986.1997.tb02140.x.

8. Maximov AL. Informative value of changes in hand skin temperature in response to hypoxic exposure. Human Physiology 2005; 31(3): 108 117. Russian. https://elibrary.ru/item.asp?id=9144833.

9. Baevskiy RM, Ivanov GG, Chireykin LV, Gavrilushkin AP, Dovgalevsky PYa, Kukushkin YuA, et al. Analysis of heart rate variability when using different electrocardiographic systems (methodical recommendations). Journal of Arrhythmology 2001; (24): 65-87. Russian. http://www.vestar.ru/atts/1267/24baevsky.pdf.

10. Heart rate variability. Standards of measurement, physiological interpretation, and clinical use. Task Force of the European Society of Cardiology and the North American Society of Pacing and Electrophysiology. Eur Heart J 1996; 17(3): 354-381. https://pubmed.ncbi.nlm.nih.gov/8737210.

11. Borovikov V. Statistica. The art of analyzing data on a computer: for professionals. Spb.: Piter, 2003; 688 p. Russian. http://medbooks.by/ozz/4963-statistica-iskusstvo-analiza-dannyh-nakompyutere-borovikov-v-2003-god-688-s.html.

12. Goldberger J, Kadish A. Influence of sympathetic and parasympathetic maneuvers on heart rate variability. In: Noninvasive Electrocardiology: 
Clinical Aspects of Holter Monitoring. A.J. Moss, S. Stern, eds. London, United Kingdom: W.B. Saunders Company Ltd., 1995: 207-223.

13. Perini R, Orizio $C$, Baselli $G$, Cerutti $S$, Veicsteinas A. The influence of exercise intensity on the power spectrum of heart rate variability. Eur $J$ Appl Physiol Occup Physiol 1990; 61(1-2): 143-148. https://doi.org/10.1007/bf00236709.

14. Stein PK, Bosner MS, Kleiger RE, Conger BM. Heart rate variability: a measure of cardiac autonomic tone. Am Heart J 1994; 127(5): 1376-1381. https://doi.org/10.1016/0002-8703(94)90059-0.

15. Karavaev AS, Kiselev AR, Gridnev VI, Borovkova El, Prokhorov MD, Posnenkova OM, et al. Phase and frequency locking of $0.1 \mathrm{~Hz}$ oscillations in heart rhythm and baroreflex control of arterial pressure by respiration with linearly varying frequency in healthy subjects. Fiziol Cheloveka 2013; 39(4): 93-104. Russian. https://pubmed.ncbi.nlm.nih.gov/25486835.

16. Goldstein DS, Bentho O, Park MY, Sharabi Y. Low-frequency power of heart rate variability is not a measure of cardiac sympathetic tone but may be a measure of modulation of cardiac autonomic outflows by baroreflexes. Exp Physiol 2011; 96(12): 1255-1261. https://doi.org/10.1113/expphysiol.2010.056259.

17. García-González MA, Vázquez-Seisdedos C, Pallàs-Areny R. Variations in breathing patterns increase low frequency contents in HRV spectra. Physiol Meas 2000; 21(3): 417-423. https://doi.org/10.1088/0967$3334 / 21 / 3 / 307$.

18. Lugliani R, Whipp BJ, Seard C, Wasserman K. Effect of bilateral carotidbody resection on ventilatory control at rest and during exercise in man. N Engl J Med 1971; 285(20): 1105-1111. https://doi.org/10.1056/nejm197111112852002.

19. Pitsikoulis C, Bartels MN, Gates G, Rebmann RA, Layton AM, De Meersman RE. Sympathetic drive is modulated by central chemoreceptor activation. Respir Physiol Neurobiol. 2008; 164(3): 373-379. https://doi.org/10.1016/j.resp.2008.08.010.

20. Somers VK, Abboud FM. Chemoreflexes - responses, interactions and implications for sleep apnea. Sleep 1993; 16 (8 Suppl): S30-S34. https://doi.org/10.1093/sleep/16.suppl_8.s30.

21. Ponikowski P, Chua TP, Piepoli M, Ondusova D, Webb-Peploe K, Harrington $D$, et al. Augmented peripheral chemosensitivity as a potential input to baroreflex impairment and autonomic imbalance in chronic heart failure. Circulation 1997; 96(8): 2586-2594. https://doi.org/10.1161/01.cir.96.8.2586t.

Authors:

Inessa V. Averyanova - PhD, Leading Researcher, Laboratory for Physiology of Extreme States, Scientific Research Center "Arktika", Fareastern Branch of the Russian Academy of Sciences, Magadan, Russia. http://orcid.org/0000-0002-4511-6782. 